\title{
Senso, de L. Visconti
}

Carlos Gatti Murriel

\section{Resumen}

El autor comenta la película Senso, de Luchino Visconti, a la cual señala como una exaltación melodramática de la sensorialidad en sus diversos matices estéticos. Para el autor, en la película, el amor que se despierta a partir de la información que ingresa por los sentidos y genera pasión lleva a perder el sentido y se convierte en causa trágica de muerte. Así, eros conduce al triunfo de thánatos, lo cual es, de algún modo, un contrasentido o un sinsentido.

Palabras clave: Senso, Luchino Visconti, sentidos, amor, muerte, eros

\section{Abstract}

The author talks on Luchino Visconti's Senso film as a melodramatic exaltation of sensory in different aesthetic ways. For him, love that wakes from sensorial information and creates passion ends in a lost of consciousness and become a tragic death cause. So, eros leads to thanatos' triumph wich is a contradiction.

Key words: Senso, Luchino Visconti, senses, love, death, eros

$\ll \bigvee \begin{aligned} & \text { elodrama», "Visconti» y «Senso» son tres palabras de las que creo que conviene } \\ & \text { partir para disponernos a entrar en el mundo unitario y, en algún sentido, }\end{aligned}$ circular (redondo) de esta obra.

La primera de esas palabras, «melodrama», está referida a un género artístico que concentra gran poder de conmoción; la segunda, «Visconti», designa a un artista, un técnico, poseedor de una sabiduría capaz de revelar con maestría las profundidades del alma humana; la tercera, "Senso», nombra a una obra, una película, en la que el tema es el amor vivido trágicamente. Melodrama a lo Visconti (el reflejo de Visconti en el melodrama) y Visconti a lo melodramático (el reflejo del melodrama en Visconti) dan origen a Senso, producto, obra de arte cargada de visiones y experiencias especulares, y de reflejos, en la que los caminos del amor (el eros) conducen a la muerte (thánatos). En esta obra, lo estético (sensorialidad y 
belleza) no lleva hacia lo ético (el bien), sino soporta a una serie de traiciones individuales y colectivas, personales y políticas, microhistóricas y macrohistóricas, todas ellas superpuestas.

Para desbrozar el terreno, me permitiré plantear algunas reflexiones sobre aquello a lo que remiten los tres términos anunciados: «melodrama», «Visconti», «Senso».

Melodrama es un término plurisignificativo, equívoco, que ha ido adquiriendo matices significativos variados con el transcurso del tiempo.Como ya saben, etimológicamente la palabra está formada con dos raíces griegas: $\mu$ é̉os (mélos), 'canto con acompañamiento musical', y $\delta \rho \tilde{\alpha} \mu \propto$ (dráma), 'drama', 'tragedia', 'suceso trágico'. Según señala Michel Brenet en su Diccionario de la Música, el melodrama es "género de espectáculo que consiste en un monólogo accionado y hablado, sostenido por la música discreta de una orquesta» (1976: 317). Menciona como primer modelo de melodrama, en esa acepción, al Pigmalión (1762) de Jean Jacques Rousseau, obra cuya partitura, salvo dos fragmentos que pertenecían al propio Rousseau, era obra de Horacio Coiguet. El mismo Brenet anota también que «algunas de las primeras óperas italianas habían sido llamadas melodramma per música» (1976: 317). Y después destaca que «en nuestros días, el melodrama es un drama popular, del que ha desaparecido la música casi enteramente» (1976: 317). Brenet registra otras acepciones de la palabra. Así dice: «2- Breve obra instrumental que se toca en el teatro durante una escena hablada. 3-Vulgarmente se denomina melodrama al drama de acción complicada y espeluznante con escenas jocosas, destinado a despertar curiosidad y emoción en público de bajo nivel cultural» (1976: 317).

Si repasamos el DRAE, vigésima segunda edición (2001), también nos topamos con diversas acepciones que paso a enumerar.

1-Obra teatral, cinematográfica o literaria en que se exageran los aspectos sentimentales y patéticos.

2- ópera (obra teatral cuyo texto se canta con acompañamiento de orquesta).

3- Letra de esta obra.

4-Drama que se representa acompañado de música instrumental en varios de sus pasajes.

5- coloq. Narración o suceso en que abundan las emociones lacrimosas.

En las acepciones segunda y cuarta registradas en el DRAE para la palabra «melodrama» se conserva la referencia a la música; es decir, en ellas queda la presencia de lo 
anunciado por la raíz mélos. En cambio, en las acepciones impares no se pone el énfasis en lo aludido en la primera parte de la palabra, mélos, sino en la segunda, dráma.

Si bien la música ha estado (o estuvo) asociada al género, ya no lo está necesariamente. Tal vez la palabra haya ido desplazando su significado mediante un mecanismo basado en el principio de la causalidad. Si la música era causa de efectos anímicos profundos en el espectador, el significado primero del término «melodrama» se pudo haber establecido teniendo en cuenta a tal causa. Luego el significado del término pudo haber pasado a aludir o a centrarse en la referencia a los efectos emocionales y ya no a lo que los causaba. Es normal que la música se asocie a lo emocional e incluso que afecte y modifique las emociones; pero cabe señalar que no solo la música puede lograrlo: hay otros medios. En el caso de la película Senso, podríamos notar que diversas acepciones de la palabra se superponen y funcionan efectivamente. De hecho, es una obra cinematográfica en la que se exageran los aspectos sentimentales y patéticos; es un drama que se representa acompañado de música instrumental generadora de climas intensos, y capaz de comentar efectivamente las situaciones por las que atraviesan los personajes. La obra se presenta con la teatralidad de una ópera, más aún, es el relato de una historia que empieza en una función de ópera y que convierte al melodrama operístico de El Trovador de Verdi, la obra que se representa en el fastuoso teatro de La Fenice de Venecia, en el modelo de un melodrama trasladado a la vida de los asistentes a dicho espectáculo: la vida es espejo del teatro y el teatro musical es espejo de la vida.

Es interesante resaltar cómo al principio de la película la cámara se dirige horizontalmente a lo que está aconteciendo en el escenario del teatro. Mientras se presentan los créditos de la película asistimos al final del acto tercero de El Trovador, ópera de Giuseppe Verdi inspirada en un drama del mismo título, obra de Antonio García Gutiérrez. En el escenario, mientras se oye la música delicada del órgano de una capilla vecina, Manrico habla a su amada Leonora de un amor sublime.

Él dice:

L'onda de' suoni mistici

Pura discende al cor!

Vieni; ci schiude il tempio

Gioie di casto amor. 
¡La onda de los sonidos misticos

Pura desciende al corazón!

Ven; nos abre el templo

Júbilos de casto amor.

Este clima idílico es interrumpido por la aparición de Ruiz, quien informa a Manrico que han tomado prisionera a la gitana y que ya han encendido la pira para quemarla. Manrico se altera y revela a Leonora que es hijo de la gitana. Conmovido por la situación entona la famosa aria "Di quella pira». Ahora vemos la escena desde arriba, en una toma en picada. Manrico ha avanzado a la parte delantera del escenario y dirige su canto airado y rebelde hacia el público.

\section{Era ya hijo antes de amarte, \\ No puede frenarme tu martirio.}

Son palabras que aluden a la amada Leonora y que anuncian un cambio dramático respecto a las dulces expresiones de amor pronunciadas poco antes. Hay que postergar a la novia por acudir en auxilio de la madre:

$$
\begin{aligned}
& \text { ¿Madre infeliz, corro a salvarte, } \\
& \text { O contigo por lo menos corro a morir! }
\end{aligned}
$$

Como consecuencia de todo ello, los compañeros de Manrico se sienten incitados a la acción y cantan con él lo siguiente:

$$
\begin{aligned}
& \text { ¡A las armas!, ¡a las armas! Henos prestos } \\
& \text { a empuñar contigo, contigo a morir. }
\end{aligned}
$$

Esta escena operística surte un efecto especial en los espectadores del teatro, a los cuales vemos con la cámara desde el escenario horizontalmente y verticalmente (en contrapicada). La madre prisionera por la cual buena parte de los asistentes al teatro siente 
que debe empuñar las armas contra el opresor es Italia. En 1866, en la época del Risorgimento, de la unificación de Italia, Venecia y su región aún formaban parte del Imperio Austrohúngaro, y los patriotas venecianos conspiraban y luchaban por su incorporación al reino de Italia y su liberación del dominio extranjero. Pero volvamos al teatro de La Fenice. Acabado el tercer acto de la ópera El Trovador con la brillante aria mencionada, desde la galería alta del teatro se lanzan octavillas, papeles rojos, blancos y verdes, y ramilletes de flores con esos colores de la bandera italiana, y se escuchan gritos de apoyo a la liberación de Venecia. El episodio de la ópera ha generado un efecto de rebote: del escenario de la ficción se ha proyectado el drama, o la conciencia del drama, hacia los espectadores, hacia la vida real de la historia, de la historia nacional italiana.

En el marco de este incidente, una veneciana patriota, movida por razones pragmáticas y altruistas, busca conversar con un oficial austriaco a fin de evitar una situación difícil para la causa de la integración de Venecia al nuevo reino de Italia; pero, con ello, abre la puerta a una tragedia que no podía prever: termina enamorada del militar austriaco y traicionando a la causa nacional. Así surge un melodrama que refleja en alguna medida, en el terreno de la pequeña historia personal, la situación que en la citada ópera de Verdi se creará entre Leonora y el Conde de Luna, aunque en tal obra la heroína no se enamora del Conde enemigo, sino que ella lo usa con engaños y luego se suicida por no traicionar a su amor y su ideal. De este modo, entre unos asistentes a la representación teatral del melodrama verdiano nace una situación vital de carácter melodramático trágico.

El Trovador, la ópera de Verdi, compositor italiano, caracteriza a la parte inicial de la película, en la que Visconti presenta al heroísmo romántico movido por ideales que pueden llevar a la renuncia y hasta la muerte por un fin noble. Al respecto, cabe destacar que Verdi fue una figura emblemática de la unificación de Italia. Lo fue tanto, que su apellido era usado como acrónimo asociado a la propaganda de la causa del nuevo reino que aspiraba a unir a todos los italianos. Las letras del apellido de Verdi se escribían en las paredes de las ciudades porque eran las iniciales de la frase «Vittorio Emmanuele Re d' Italia». En efecto, la monarquía que aspiraba a construir la unidad de Italia tenía como cabeza al rey Víctor Manuel II.

El melodrama de la condesa Livia Serpieri, patriota italiana que traiciona a su causa por la pasión que le suscita el teniente Franz Mahler, lleva como comentario musical a pasajes de la sétima sinfonía del compositor austriaco Anton Bruckner, autor de sinfonías que encarnaba el espíritu musical germano. En cuanto la condesa Serpieri cae en las garras del 
cínico teniente Mahler, el italiano Verdi queda atrás, y la música germánica e instrumental es la encargada de perfilar las profundidades de la psique humana y de comentar la tragedia del alma en proceso de desmoronamiento. Bruckner puede ser considerado un compositor epigonal del sinfonismo romántico y uno de los músicos asociados al crepúsculo del Imperio Austro-húngaro. Si en la ópera de Verdi puesta en el escenario era necesario que Manrico se separase de la amada para ir en defensa de la madre, liberarla o morir por ella, en los palcos del teatro, una hija fervorosa de la madre Italia inicia una vinculación amorosa con uno de los dominadores y abandona la causa de la lucha por la libertad de su patria, incluso traicionando a sus compañeros de ideales, los cuales tienen su representante más visible en el marqués Roberto Ussoni, primo de la condesa Livia Serpieri. Si Ussoni es el fiel a la causa, el héroe romántico dispuesto a morir por rescatar a la madre Italia como Manrico del Trovador, la Serpieri es la traidora que antepone la sensorialidad de un amor no casto a los ideales nacionales y a la fidelidad conyugal. Ganada por la pasión, su historia de decadencia moral es comentada por la música del austriaco Bruckner.

Con el desarrollo de la acción se ve cómo la aristocrática condesa Serpieri vaga por las callejuelas oscuras de la decadente Venecia, cómo pierde su condición de superioridad social y pasa a convertirse simplemente en Livia para el militar austriaco. A partir de entonces, y luego de un breve período de encuentros apasionados, Livia, ya muy enamorada, descubre que Franz no corresponde a su amor con la misma intensidad con la que ella lo vive, lo que la destruye moralmente y la rebaja a una condición humillante en la que cobra plena conciencia de la pérdida del pudor. Pero no solo ella desciende. También Franz Mahler sufre una degradación moral. Ante la inminencia de la guerra entre los austriacos y las fuerzas del nuevo reino de Italia, aliado a Prusia, rival de Austria, él traiciona a su propia patria y soborna a unos médicos a fin de que lo declaren inapto por razones de enfermedad. Para ello vuelve a buscar a Livia, a la cual convence para que le consiga el dinero necesario para concretar el soborno. Ella le entrega las joyas y monedas que su primo Ussoni le había dado en custodia para financiar la campaña de los patriotas italianos. De este modo, si Livia ha traicionado a su patria, Franz también traiciona a la suya, a Austria; pero luego de aprovecharse de Livia, también a ella la traiciona. Ante ello, la mujer, ofendida y rebajada a niveles abyectos, traiciona al amante mediante una denuncia ante sus jefes militares. La película concluye con el fusilamiento de Franz Mahler, acontecimiento que es encuadrado por la cámara verticalmente en picada, como en aquella escena de los comienzos de la película cuando desde lo alto se ve el melodrama del Trovador en el momento en que 
Manrico entona el aria «Di quella pira» con la que se define su compromiso guerrero e incita a tomar las armas.

¿Cómo y por qué se conocieron Livia y Franz? En la revuelta producida en el teatro al final del tercer acto de la representación del Trovatore, el teniente Franz Mahler, presente en la platea del teatro, pronuncia palabras de desprecio por el patriotismo de los italianos. A ello responde el primo de Livia, el aristócrata veneciano Roberto Ussoni, quien desafía a duelo a Mahler ante la mirada de quienes ocupan la platea y los palcos inmediatos, donde se encuentran las autoridades militares austriacas asentadas en Venecia. El marido de Livia está con ella en el palco del jefe militar austriaco. Si bien Livia es una patriota, su marido, un noble italiano que hace su aparición hablando en alemán, se siente un súbdito del Imperio Austriaco. Él trata de excusar lo sucedido y pretende dejar en claro que Ussoni es un pariente lejano y poco allegado a su casa. En cambio, Livia, que está preocupada por la suerte del primo y por la causa nacional italiana, busca el modo de ayudar al pariente. Pide conversar con el teniente Mahler a fin de evitar el duelo, y el jefe militar hace llamar al teniente a su palco. Livia se quita el velo. Luego, se mira en un espejo y en este se refleja el telón que sube para dar inicio al cuarto acto del Trovador, el melodrama que se representa en el escenario. Noche oscurísima, una alta torre donde se encuentra prisionero Manrico, el que había intentado rescatar a su madre. Leonora, la amada de Manrico, intenta obtener gracia del Conde de Luna y le promete entregarse carnalmente a él a cambio de la libertad de Manrico y su madre. Al melodrama de Verdi se superpone ahora el de la vida real. El encuentro entre Livia y Franz se produce en el palco. En el fondo, entre ellos, en el encuadre cinematográfico, aparece la figura de Leonora, el personaje de la ópera, que marca la superposición de los dos melodramas.

Curiosamente, Livia, en conversación con el teniente Franz Mahler, sostiene poco después: «Si, a me piace l'opera, non mi piace quando si svolge fuori scena né che ci si possa comportare come un'eroe da melodramma senza pensare alle conseguenze gravi di un gesto impulsivo...». Con tales palabras, ella está tratando de impedir el duelo entre el patriota Ussoni y el teniente Mahler, consecuencia grave de gestos impulsivos; sin embargo, con este diálogo buscado por ella ha iniciado su propia tragedia y la de Mahler.

Luego Livia pregunta: «¿Puedo hablar francamente?»; y Franz responde: «Ciertamente, es la única manera que yo aprecio». El diálogo franco sobre el duelo se suscita cuando Leonora, personaje del Trovador aparece encuadrada detrás de los futuros amantes. 
Leonora encarna al personaje que engañará al Conde de Luna con la promesa de la entrega sexual a cambio de la libertad del amado y de la madre de él.

Después de intentar que Mahler desista del duelo, Livia se retira del teatro; pero ya lleva en sí la semilla de su propio melodrama. En verdad, tratar del duelo era inútil porque, como se descubrirá después, Mahler ya había actuado para que Ussoni, el noble que lo había retado, fuera desterrado: el poder del extranjero había hecho valer su fuerza.

\section{Visconti}

$\mathrm{L}$ a segunda palabra de nuestra exposición es Visconti, el apellido del director de cine Jitaliano que entre 1942 y 1976 creó películas notables basadas, en muchos casos en textos literarios como Los Malavoglia (de Giovanni Verga), Senso (de Camillo Boito), Las noche blancas (de F. Dostoiewski), El Gattopardo (de Tomassi di Lampedusa), El Extranjero (de A. Camus), Muerte en Venecia (de T. Mann), El Inocente (de G. D’Annunzio).

Luchino Visconti nació en Milán en 1906 y murió en Roma en 1976. A lo largo de 70 años disfrutó de las ventajas de una posición social alta y de una formación cultural riquísima que aflora en todas sus obras. Fue gran conocedor de música (interpretaba el violonchelo), de ópera, de teatro, de literatura, de artes plásticas y de cine. En todas sus obras cinematográficas se puede observar la maestría con la que combina las artes y elabora mundos cargados de riqueza estética y de sutilezas que envuelven al espectador en un nimbo poético inagotable y de gran potencia sugeridora.

Después de haber sido asistente de dirección de Jean Renoir, en sus inicios como director, cultivó el neorrealismo. La terra trema incluso fue filmada en lengua siciliana con pescadores de la localidad de Acitrezza para lograr una mayor aproximación al mundo popular de los pobres de la isla de Sicilia.

A partir de Senso, primera película que filmó en color, en 1954, abrió una tendencia esteticista centrada en su interés por presentar la decadencia del mundo aristocrático al cual él pertenecía por origen familiar. El Gatopardo y Ludwig son películas que, como Senso, tratan de episodios históricos relativos a la pérdida del sentido y la decadencia de los viejos ideales aristocráticos.

En Senso, Visconti presenta una relectura crítica del Risorgimento, el proceso de unificación italiana; pero también presenta el ocaso del viejo Imperio Austro-húngaro. En efecto, hacia el final de la película el teniente Mahler comenta que si bien los austriacos 
han ganado a los italianos en la batalla de Custozza, sabe que Austria perderá la guerra y el viejo orden será reemplazado por un nuevo mundo que surgirá. En ese contexto de miedo y de pérdida de sentido de un mundo centrado en el gozo del presente (mentalidad estética), el teniente Mahler se hace desertor y traiciona a su patria. Ante la inminencia del fin, Visconti, como sucede con el crepúsculo o el otońo, exacerba los sentidos con la riqueza de sus matices sensoriales. Como el cisne canta solo antes de morir, así Visconti se entrega al culto de la belleza movido por la conciencia de la proximidad de la muerte. El teniente Mahler solo creía en el gozo del presente y en la contemplación de su figura reflejada en el espejo, en una actitud narcisista e inmediatista propia de quien no está bien dispuesto para el verdadero amor ni para el compromiso con una causa; es decir, estaba ganado por la mentalidad estética y era ajeno a la mentalidad ética.

Si bien Visconti era un aristócrata por su origen familiar, su formación y sus gustos, él en un momento de su vida abrazó la ideología marxista. Sus películas son testimonio de esta paradójica combinación.

Se ha dicho que poco antes de dedicarse a filmar la película Senso, Visconti estaba preparando el montaje de la ópera El Trovador para presentarla en Florencia, pero lo vetaron por sus ideas políticas. También se comentó que Senso no ganó el premio del Festival de Venecia porque Visconti, con su visión decadente y crítica, había dañado de algún modo la imagen ideal del proceso del Risorgimento y la unificación de Italia.

\section{Senso}

L a tercera palabra sobre la cual quisiera reflexionar corresponde al título de la película Senso. Este es un término plurisignificativo y muy sugerente. Visconti lo tomó del nombre de la novela en la que se inspiró. En efecto, Senso es la última novela (relato corto) que integra la segunda colección de Storielle vane, aparecida en 1883, obra de Camillo Boito, hermano de Arrigo Boito, el libretista de las últimas operas de Verdi y compositor de ópera.

En Senso, de Camillo Boito, el relato se plantea a partir del diario de la protagonista, la cual, a los 39 años de edad (al borde de concluir la cuarta década), se cuenta a sí misma la relación que a los 22 ańos había mantenido con un teniente austriaco, del cual entonces se había enamorado. La pasión la había llevado al adulterio, luego a la desesperación y, finalmente, a la humillación, cuando descubrió que su amante, Remigio, solo estaba 
interesado en conseguir de ella el dinero para desertar. Traicionada y ultrajada, Livia denuncia al teniente a las autoridades austriacas, las cuales lo condenan a muerte junto al médico que, por dinero, lo había declarado inapto para el servicio.

Pienso que Visconti ha recogido el carácter de diario que Boito ha dado a su narración mediante el recurso de la voz en off de Livia. Nótese en la película, por ejemplo, el momento en que ella sale de la sala del teatro La Fenice a buscar a su primo, el marqués Ussoni.

En Boito, Livia se siente una filósofa movida por el deseo de conocerse a sí misma. Por eso recurre al diario, la memoria, el autoanálisis. En su diario recuerda al amante austriaco como una mezcla de Adonis y Hércules, bello y vigoroso, pero vil. En sus páginas, abundan las descripciones pictóricas, y una sensorialidad intensa, muy bien recogida por Visconti en la película. Ella cuenta cómo a los 22 años se casa y va de viaje de bodas a Venecia, ciudad que le hablaba más a los sentidos (sensi) que al alma: el esmeralda de las aguas de la laguna, los crepúsculos dorados, el negro de las góndolas, las callejuelas oscuras.

Si bien el argumento de la película de Visconti se aparta de la novela en diversos detalles, el cineasta ha sabido aprovechar lo mejor del relato de Boito y desarrollarlo con la solvencia de un artista inteligente y sensible.

Entre otros aspectos de la novela que pueden haber influido en la película de Visconti, podrían mencionarse el sensorialismo de Livia y del amante, que da título tanto al relato de Boito como a la película, y algunas frases concretas que debieron de atraer especialmente la atención del director. Hay un pasaje en la novela en el que la protagonista menciona que no encuentra otra confortación, o consuelo, que su espejo. En la película la presencia de los espejos es permanente, y no solo como elemento formal de la decoración de interiores. Ellos sirven para la construcción de la narración, para superponer acciones y para presentar el carácter de reflejo que se suscita entre lo que sucede en el escenario y lo que pasa en la vida. En ellos se retratan los personajes. En ellos los personajes pueden observar lo que sucede detrás, y con ellos también el espectador de la película puede percibir espacios más amplios, acontecimientos periféricos y reflejos que lo involucran. Así, arte y vida se corresponden y se reproducen una en otra. Un detalle de la película que merece destacarse, a propósito de lo mencionado, está relacionado con el fragmento de espejo que Mahler encuentra en una plaza de Venecia, el cual sirve para poner en evidencia a la personalidad narcisista de ese personaje. 
En otro momento del relato de Boito, Livia habla de la inconstancia de los hombres y la falta de solidez de las pasiones pues se ha enterado por la criada de que un joven abogado, que la asediaba y le juraba amor eterno, ha decidido casarse. Estas son las palabras que Livia pone en boca de ese joven y que en alguna oportunidad él había dicho: «Condesa Livia, muero, me mato; su imagen desaparecerá de mi pecho con la última gota de mi sangre; píseme como a un esclavo, pero permítame adorarla como a una diosa». Ella añade: «Frases de melodrama. Pocos meses, y todo se desvanece. Amor, furor, juramentos, lágrimas, sollozos, ¡no queda nada! Asquerosa naturaleza humana».

Con su película, Visconti elevó lo que anuncian estas palabras a niveles de gran altura dramática. Deseo destacar cómo el carácter melodramático de la ópera y el lujo del teatro veneciano de La Fenice, con que empieza la película, se traslada a los escenarios de la vida real donde se interpreta, como reflejado en el espejo, un nuevo melodrama. Y esos escenarios están recargados de objetos de arte y espejos (reparemos en la villa Aldeno ubicada en el campo, donde se refugian Livia y su familia desde el momento en que está por empezar la guerra, o fijémonos en el departamento que ocupa el desertor Mahler en la ciudad de Verona). El carácter melodramático del que expresamente habla el diario de la Livia de Boito está acentuado por el modo de comportarse de los personajes de la versión de Visconti, quienes más parecen estar sobre un escenario teatral que en la vida cotidiana.

Un rasgo que considero muy sugerente y que aparece en varios momentos de la película es el modo de desplazarse de Livia por corredores o callejuelas. Podemos verla buscando apoyo en las paredes o los muros, a modo de evidencia del descentramiento en el que ha caído y de la debilidad que le ha generado la pérdida de rumbo por el abandono de los ideales y la entrega a una pasión descontrolada.

Otro rasgo de esa vida convertida en realidad teatral podría percibirse en la presencia de espectadores reales (como la mucama, Laura, que husmea en la vida de su patrona, la mujer que alquila la habitación usada por los amantes para sus encuentros, los compañeros de milicia de Franz que son testigos de las visitas de Livia y de sus búsquedas del amante esquivo) o también de espectadores ficticios (como las figuras pintadas en las paredes de la villa Aldeno, o las representadas en los cuadros colgados en las paredes). También cabe destacar cómo Franz Mahler parece buscar la mirada de los que espectamos su hipócrita actuación cuando, recostado sobre el regazo de Livia, pronuncia palabras de amor; pero está más interesado en recoger del suelo y llevarse las monedas y las joyas caídas del cofre 


\section{CARLOS GATTI MURRIEL}

que Livia había recibido en custodia y que debían servir para financiar la causa patriótica italiana.

Volvamos al carácter plurisignficativo del nombre de la película. La palabra senso proviene del latín sensum, forma derivada de sentire 'percibir'. En castellano la palabra italiana senso equivale a 'sentido'. Tanto en la palabra italiana, como en la correspondiente castellana, se da una polivalencia de significado. Senso puede entenderse con valor asociado a la sensualidad, a los impulsos ligados al instinto; a la percepción de estímulos externos, o internos; a la actividad sensorial asociada a la vida; a la sensibilidad; al significado en tanto valor semántico; a la dirección que toma alguien o algo; a la razón de ser y la finalidad de algo.

En la película, Livia y su amante son personas en proceso de entrega (ella) o ya ganadas (él) por la sensorialidad. Franz Mahler muestra esa condición desde que llega al palco y mira descaradamente el pecho de la condesa que lo ha hecho llamar a fin de interceder para evitar el duelo entre el teniente y su primo Roberto Ussoni. La condesa se percata de la mirada y se cubre el pecho con el velo y, luego de haber dicho lo que tenía que decir, alega un malestar y se retira del teatro cuando se está representando el cuarto acto del Trovador. En ese momento quien sale de La Fenice aún es una mujer comprometida con un ideal, una patriota italiana dispuesta a apoyar la causa política de la unificación. Su vida tiene una razón de ser, una dirección: encierra sentido (senso). Es una mujer que piensa en el futuro, con mentalidad ética, según el criterio de Kierkegaard. Es una mujer con visión emprendedora, a pesar de estar casada con un italiano atado al poder austriaco, lo que podía asegurar a ella una vida cómoda y mantenerla en una actitud conservadora. Como Dido en la Eneida, Livia trabaja en la construcción de una empresa política: tiene una misión que implica a otros. Pero, como sucedió a la reina Dido con el extranjero Eneas, la figura de Mahler la ha inquietado y en ella se empiezan a encender los fuegos del amor. El encuentro casual con Mahler en las calles de Venecia, días después del episodio del teatro, inflama a la pasión. Así, Livia se va desviando de su misión y de la acción que le correspondía como patriota comprometida y consecuente. El yo ideal de Livia, vinculado con su compromiso patriótico, es vencido por las pulsiones de la sensualidad, por el «ello». La acción cede paso a la pasión y la empresa de construcción de la patria (Cartago en el caso de Dido; Italia en el de Livia) queda olvidada.

En la Eneida se dice que el pudor había mantenido a la reina Dido fiel a la memoria de su difunto marido Siqueo; pero con la llegada de Eneas a las playas de Cartago y como 
consecuencia de los consejos de Ana, hermana de Dido, en esta reina cesó la voz del pudor, se entregó al extranjero y abandonó la construcción de su ciudad, su empresa política. De igual modo, Livia, fiel hasta un momento a su casi ausente o casi difunto marido, por decirlo con imágenes que buscan destacar la distancia existente en diversos terrenos entre los cónyuges, no solo pierde su pudor, sino que lo reconoce y lo declara en la casa de campo de la localidad de Aldeno. La diferencia entre ambas mujeres reside en que después de seducida y abandonada, Dido se suicida, mientras que, después de pasar por parecida situación, Livia denuncia al amante y es él quien muere a manos de sus compatriotas y compañeros de armas.

Mahler era un sensorialista, entregado a los sentidos (sensi) que vivía cínicamente solo en el goce del presente (personalidad estética). Él desvió a Livia de su condición ética (orientada al futuro y la acción) y la enredó en una pasión sin futuro. Así, pues, ella desembocó en una situación trágica, infeliz, en una vida sin sentido (sin finalidad). Podríamos resumir esto en la siguiente formulación. Livia, la protagonista del melodrama, abandonó el sentido de su vida para convertirse a una vida centrada en los sentidos, la sensorialidad y el goce inmediatista de una pasión. Ella terminó viviendo un sinsentido ya que su vida perdió finalidad.

La película de Visconti es una exaltación melodramática de la sensorialidad en sus diversos matices estéticos (no olvidemos que la palabra aỉoӨnoıs, de donde viene el término estética, encierra un valor equivalente al de sensación, senso). En la película, el amor que se despierta a partir de la información que ingresa por los sentidos (senso) y genera pasión lleva a perder el sentido (senso en tanto rumbo, dirección y seso) y se convierte en causa trágica de muerte. Así, eros conduce al triunfo de thánatos, lo cual es, de algún modo, un contrasentido o un sinsentido.

Podría concluir esta exposición apelando a una sugestiva figura retórica aplicable a este melodrama: Senso senza senso (sentido sin sentido, sensorialidad sin rumbo). ¿Era esa, tal vez, la visión de Visconti respecto a la antigua aristocracia de la segunda mitad del siglo XIX que propició la unificación de Italia? 


\section{Bibliografía}

Brenet, Michel

1978 Diccionario de la música. Barcelona: Iberia.

VIsCONTI, Luchino

1954 Senso. Italia. $117 \mathrm{~min}$. 